\section{Even 'free access' is still beyond the means of most scholars in Africa}

Sir - The draft sequence of the human genome (Nature 409, 814-958; 2001) is a landmark achievement that will satisfy intellectual curiosity and biotechnological ambitions for a considerable time. Nature is to be applauded for its open publication of the sequence and the many excellent research articles and analyses that accompany it. However, although freely available, access is far from free for all.

Here in west and central Africa we inhabit a communication wasteland, with only fragmentary evidence of the electronic capacity of the twenty-first century. Faced with computer scarcity, limited bandwidth connectivity to the Internet, and few skilled educators to explain molecular biology, access to the human genome sequence is not free. Journal availability throughout the whole region is virtually non-existent, and the costs of personal subscriptions prohibitive. In contrast, all editions of Nature and many other journals are indeed freely available to most students and researchers in Europe and North America, through institutional subscriptions.

Africa came away from the green revolution empty handed; the biotechnology revolution has all but passed it by. If Africa is to exploit the new-found knowledge of the human genome and to participate effectively in the biotechnology revolution, the bottlenecks must be removed.

One critical constraint is access to information. With modest donor support and the goodwill of publishers, online access to journals, books and patents could inspire students and teachers with the latest scientific discoveries, rejuvenate the aspirations of researchers, and provide policy-makers with insights into issues such as biosafety, intellectual property and commercial opportunities. Online information could provide a keystone for Africans to develop innovations that tackle African needs in a continent ravaged by HIV, malaria, malnutrition and poverty. Paul Keese

International Institute of Tropical Agriculture, Oyo Road, Ibadan, Nigeria

\section{Precarious life in Spain}

Sir-As you have frequently reported, Spanish scientists face many obstacles in their funding and careers (see, for example, Nature 408, 397 \& 405, 723; 2000). Young Spanish researchers lack employment rights such as affiliation to the social security system or health benefits. They depend on grants and are considered by the government as students, yet they have to pay tax and must engage exclusively in research and lecturing.

Pre- and postdoctoral scientists are usually not represented in the elected body of their centres. Further, because of the pyramidal structure of the Spanish career system, young researchers have fewer opportunities as they become more senior. Often their careers are interrupted while awaiting the next grant, yet they receive no unemployment benefits. The situation is even worse in light of Spain's small research budget, few new permanent positions and nepotism in some research centres.

In February, more than 4,000 young researchers denounced this situation in front of the Ministry for Science and Technology in a demonstration organized by a group called Precarios: the Young Researchers' Federation. Their name recalls both the Spanish word for people on a grant, becarios, and their precarious situation (see http://www.precarios.org). They presented a manifesto signed by some 3,000 senior Spanish scientists, demanding a new status for young researchers, including social benefits and an increase in investment in R\&D budgets.

Proper recognition in the early stages of scientific careers is a necessary step towards the inclusion of Spain in the group of scientifically most advanced countries. Manuel J. Pérez Mendoza, for Precarios Grupo de Investigación en Carbones, Departamento de Química Inorgánica, Universidad de Granada, Av. Fuentenueva s/n., 18071 Granada, Spain

\section{Let's reward innovative action against poverty}

Sir - Each year, the world rightly honours the best contributors to science, economy, literature and peace. However, these accolades stop short of their ultimate objective, which is the improvement of the human condition, especially where living conditions are atrocious. There is no commensurate recognition for scientific work that directly improves the quality of life of the poor and underprivileged.

It should not be difficult to design such a prize, because there are now indicators to measure socioeconomic development. What has emerged is that science, technology, creative economic principles, elegance in literature and even sacrifices for peace do not in themselves reduce poverty and alienation. Progress requires deliberate attempts to link these advances with efforts to provide basic needs, empower the poor and banish inequity and injustice.

What should be singled out for support and commendation are ways to bring together knowledge and grass-roots community action. Underdevelopment is the greatest threat to world peace and global environmental security, and therefore deserves special intellectual and scientific consideration. A serious, wellpublicized prize to honour those who have used imagination and innovation to push back disease, deprivation and injustice is the most important prize of all, if the objective is survival of a civilized planet. Arnoldo Ventura

Office of the Prime Minister, 1 Devon Road, Kingston 6, Jamaica, West Indies

\section{Entropy illustrates the flexibility of Chinese}

Sir - The Words essay by Alan L. Mackay (Nature 410, 19; 2001) illustrates the challenges that the Chinese language faces in the new millennium. As a native speaker, I would like to offer a different, perhaps more accurate interpretation of the etymology of the character 摘 (shang), which means 'entropy'.

The translation of entropy into 摘 is a perfect example of the adaptive nature of the Chinese language. It reflects the equation $S=H / T$, where $S$ is entropy, $H$ is enthalpy (焓— han), and $T$ is the absolute temperature. The left half, 火 (fire), hints that the character 摘 has something to do with heat or temperature, and the right half, 商, means 'quotient' instead of Mackay's interpretation of 'merchant'.

This difference is understandable, as an English speaker who knows the Greek word-root trope, which denotes turning and changing, would naturally associate the character 商 with 'merchant'. But an educated Chinese speaker does not readily associate a scientific character such as 摘 with a merchant. In the traditional Chinese value system, merchants were considered not quite highbrow. The association with quotient is much more spontaneous, as a difficult character such as 摘 confers an implicit sense of being about learned matter.

The translation of enthalpy to 焓 is equally exquisite. The left part of the character means 'fire' as in entropy; the right part, 含, means 'content'.

These are just two examples of how new Chinese characters were coined as the need arose. None of the new characters that I know of was created de novo, in keeping both with the long tradition of the language, and with its creativeness and adaptability. Jian Feng (冯简)

Department of Physiology and Biophysics, State University of New York at Buffalo, 124 Sherman Hall, Buffalo, New York 14214, USA 